\title{
SYNTHESIS AND SCREENING OF SOME AZOMETHINES BEARING METHYL SALICYLATE MOIETY FOR ANTIBACTERIAL ACTIVITIES
}

\author{
Shipra Baluja ${ }^{1 *}$ and Sumitra Chanda ${ }^{2}$
}

\begin{abstract}
1Department of Chemistry, Saurashtra University, Rajkot-360005, India 2Department of Bioscience, Saurashtra University, Rajkot-360005, India
\end{abstract}

Submitted: $28-12-2015$

Revised: $15-02-2016$

Accepted: 19-03-2016

*Corresponding author Shipra Baluja

Email:

shipra_baluja@rediffmail.com

\begin{abstract}
In this study, the series of novel azomethines were synthesized from methyl salicylate and their structural determination was done by IR, NMR and mass spectral data. The screening of these synthesized compounds were done against some Gram positive and Gram negative bacteria in DMF and DMSO solvents by agar disc method. It is observed that solvent and compound structure both affect the inhibition. DMF is found to be good solvent in the present study. Amongst all studied compounds, JB-4 showed maximum zone of inhibition against most of the studied bacterial strains while compound JB-2 is least effective. Thus, substitution affects inhibition and methyl salicylate moiety with cinnamaldehyde side chain is most effective. Further, virtual screening of these compounds was done to evaluate molecular properties and bioactive scores of these compounds.
\end{abstract}

Keywords: azomethines, methyl salicylate, antibacterial activity, agar disc method, DMF, DMSO

\section{INTRODUCTION}

The chemistry of $>\mathrm{C}=\mathrm{N}$ - is studied extensively because of its high synthesis flexibility, coordinating ability and medicinal use. The compounds containing $>\mathrm{C}=\mathrm{N}$ - group are known as an imines or azomethines or Schiff bases which are studied extensively because of their various applications, especially in medical and biological fields. Several workers have reported the applications of these azomethines in various fields such as corrosion inhibitor (Yurti et al., 2005), as complexing agents (Cegłowski and Schroeder) and as intermediate in many reactions (Ajabshir et al., 2015; Hashimoto et al., 2012: Hesping et al., 2015). Many azomethines have been known to be medicinally important and are used to design medicinal compounds (Aydogan et al., 2011 and Hoz et al., 2007) because of their wide biological spectrum such as antitumor (Asadi and Sarvestani, 2001), antifungal (Al-Amiery $e t$ al., 2012), antiviral (Verma et al., 2014), anticancer (Singh et al., 2007), anti HIV (Sriram et al., 2005), antibacterial (Pandey et al., 1999), antiproliferative (Sztanke et al., 2013) and anti inflammatory (Bekhil et al., 2003) activities.

Due to their characteristics properties like thermal stability, abnormal magnetic properties, relevant biological properties, high synthesis flexibility, varied coordinating ability and medicinal utility, in the present work, some new azomethines from methyl salicylate are synthesized. The structure of synthesized azomethines is confirmed by IR, NMR and mass spectral data. Further, antibacterial activity of these synthesized azomethines is studied in DMF and DMSO against some Gram positive and Gram negative bacteria.

In order to understand the property of chemical molecule, some molecular descriptors and their biological score have also been calculated by using molinspiration and DruLiTo softwares.

\section{MATERIAL AND METHODS}

\section{Synthesis}

Synthesis of 2-hydroxy phenyl hydrazine

A mixture of hydrazine hydrate and methyl salicylate was dissolved in methanolic hydrochloric acid and was refluxed for 6 hours. The reaction mixture was then poured in water. The product obtained was filtered, washed with water and dried. It was crystallized from alcohol.

\section{Synthesis of azomethines}

Equimolar mixture of 2-hydroxy phenyl hydrazine and substituted aldehydes was taken 
in methanol. 2-3 drops glacial acetic acid was added and the solution was refluxed for 8-10 hours. The product was isolated and crystallized from methanol.

The reaction scheme of the entire synthesis is given below:

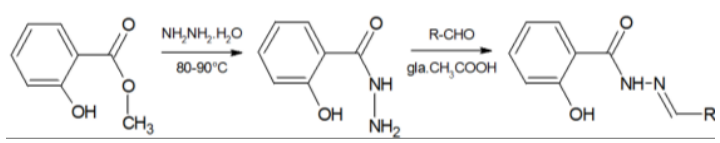

Overall, the following seven azomethines have been synthesized: JB-1:2-hydroxy- $N^{\prime}$-[(1Z)-(4methylphenyl) methyllidene] benzohydrazide; JB-2:2-hydroxy- $N^{\prime}$-[(1Z)-(4-methoxyphenyl) methyllidene] benzohydrazide; JB-3:2-hydroxy$N^{\top}$-[(1Z)-phenylmethylidene] benzohydrazide; JB-4:2-hydroxy- $N^{\prime}$-[(1E,2E)-3-phenylprop-2en-1-ylidene] benzohydrazide; JB-5:2-hydroxy$N^{\prime}$-[(1E)-(2-hydroxyphenyl) methylidene] benzohydrazide; JB-6:2-hydroxy- $N^{\prime}$-[(1E)-(2-nitrophenyl) methylidene] benzohydrazide; JB-7:2hydroxy- $N^{\prime}$-[(1E)-(3-nitrophenyl) methylidene] benzohydrazide

The various physical constants such as $\mathrm{R}_{\mathrm{f}}$ value, melting point and percentage of yield for all the synthesized azomethines (Table I).

The structure characterization of these synthesized compounds was done by Infra red, Nuclear magnetic resonance ( $\left.{ }^{1} \mathrm{H} \mathrm{NMR}\right)$ and Mass spectral data.

\section{Antibacterial activity}

All the synthesized compounds i.e., azomethines were recrystallized prior to use. The solvents DMF and DMSO were purified before use, by standard methods. The Agar disc diffusion method was adopted for the study.

Preparation of solutions of test compounds

The synthesized test compounds were dissolved in DMF/DMSO at a concentration of $10 \mathrm{mg} / \mathrm{mL}$.

\section{Test microorganisms}

The bacterial strains studied are identified strains and were obtained from National Chemical Laboratory (NCL), Pune, INDIA. The synthesized azomethines were tested against two Gram positive bacteria $B$. subtils, $S$. aureus and three Gram negative bacteria $P$. mirabilis, $S$. typhimurium and $K$. Pneumoniae.

\section{Agar disc diffusion method (Álvarez- Fernández et al.,)}

The antibacterial assay was evaluated by the method of agar disc diffusion method. The media used for the antibacterial assay were Mueller Hinton Agar No.2 and SDA media. The test strain $(200 \mu \mathrm{L})$ was inoculated into the media (inoculums size $10^{8}$ cells $/ \mathrm{ml}$ ) when the temperature reached $40-42^{\circ} \mathrm{C}$ and poured into Petri dishes. $20 \mu \mathrm{L}$ of the test compound was impregnated in to sterile discs $(7 \mathrm{~mm}$, HiMedia), allowed to dry and was introduced on the upper layer of the seeded agar plate. The plates were incubated overnight at $37^{\circ} \mathrm{C}$. The experiment was performed under strict aseptic conditions. Microbial growth was determined by measuring the diameter of zone of inhibition. For each bacterial strain, controls were maintained where pure solvent was used instead of the extract. The result was obtained by measuring the zone diameter. The experiment was done two times and the mean values are presented.

\section{Calculation of molecular descriptors and prediction of bioactivity score}

The drug likeness is related to physicochemical properties such as molecular weight, total polar surface arear (TPSA), molecular lipophilicity (i.e., $\log \mathrm{P}$ and miLogP), total number of atoms (nAtoms), number of rotatable bonds (nrotb), number of rigid bonds (nRigidB), number of hydrogen bond donors $(\mathrm{nOHNH})$ and number of hydrogen bond acceptors (nON). These physicochemical properties are associated with acceptable solubility and intestinal permeability (Lipinski). TPSA is a very good predictor of drug transport properties such as interstinal absorption, bioavailability, blood brain barrio penetration etc. Its calculation is based as a sum of fragment contributions of $\mathrm{O}$ - and $\mathrm{N}$ centered polar fragments and related to the hydrogen bonding potential of the molecule.

Various drug likeness rules such as Lipinski'rule (Lipinski et al., 1997), Ghose rule (Ghose et al., 1999), Veber rule (Veber et al., 2002) and modern drug data report (MDDR) rule [Oprea; Bardley, 2002) have been used. 
Further, one can predict the bioactivity score of compounds for drug target. Some of these scores are G-protein coupled receptor ligands (GPCRL), Ion channel modulator (ICM), Kinase inhibitor (KI), nuclear receptor ligand (NRL), Protease inhibitor (PI) and enzyme inhibitor (EI)).

For the calculation of most of the molecular descriptors and prediction of bioactivity scores, molinspiration software was used. Some other molecular descriptors are calculated by software DruLiTo.

\section{Lipinski' rule}

Lipinski's rule of five is a thumb rule to determine if a compound with a certain pharmacological activity has properties that would make it likely orally active drug. The Rule of five got its name from the cutoff values for each of the four parameters that define the potential of a drug candidate for good absorption: all of these values are close to five or a multiple of five. This rule states that the absorption or permeation of a molecule is more likely when the molecular weight is under $500 \mathrm{~g} / \mathrm{mol}$, the value of $\log \mathrm{P}$ is lower than 5 and the molecule has utmost five hydrogen bond donors and ten hydrogen bond donors atoms. There should not be more than one number of violation of this rule.

\section{Ghose filter}

This filter defines drug-likeness constraints in terms of $\log \mathrm{P}$, molecular weight, molar refractivity and total number of atoms. In this filter, calculated $\log \mathrm{P}$ is between -0.4 and 5.6, molecular weight is between 160 and 480, molar refractivity (MR) is between 40 and 130 , and the total number of atoms is between 20 and 70 .

\section{Veber's rule}

According to Veber, a compound will have a high probability of good oral bioavailability is there are less than ten rotatable bonds and Polar surface area is equal to or less than $140^{\circ} \mathrm{A}$ ( or hydrogen bond donors and acceptors are less than twelve).

\section{MDDR-Like rule}

Descriptors used to MDDR-like rule are the number of rings, the number of rigid bonds and the number of rotatable bonds. According to this rule, a compound is of drug like if number of rings is greater than or equal to three, number of rigid bonds are equal to or less than eighteen and number of rotatable bonds are greater than or equal to six.

\section{RESULTS AND DISCUSSION \\ Spectral data}

JB-1: $\mathbf{I R}\left(\mathbf{c m}^{-1}, \mathbf{K B r}\right): 3348$ (-OH str.), 2926 (sym. C-H str.), 1381 (sym. C-H def.), 3173 (sym. aromatic $\mathrm{C}-\mathrm{H}$ str.), 1516 (aromatic $\mathrm{C}=\mathrm{C}$ str.), 1620 (C=N str.), 1236 (C-N str.), ${ }^{1} \boldsymbol{H}$ NMR (DMSO-d $\boldsymbol{d}_{6}$ ) $\boldsymbol{\delta}$ (ppm): 2.39 (3H, singlet, $\left.-\mathrm{CH}_{3}\right)$, 6.88-6.91 (2H, multiplet, Ar$\mathrm{CH}), 7.21-7.23$ (2H, doublet, Ar- $\mathrm{CH}), 7.67-7.72$ $(2 \mathrm{H}$, doublet, $\mathrm{Ar}-\mathrm{CH}), 7.74-7.77(2 \mathrm{H}$, doublet, Ar- $\mathrm{CH}), 8.41(1 \mathrm{H}$, singlet, $=\mathrm{CH}-), 11.57(1 \mathrm{H}$, singlet, -NH-), $12.13(1 \mathrm{H}$, singlet, $-\mathrm{OH}), \boldsymbol{M S}$ : $(\boldsymbol{m} / z)=254.28$

JB-2: IR ( $\left.\mathbf{c m}^{-1}, \mathbf{K B r}\right): 3412$ (-OH str.), 2956 (sym. C-H str.), 1379 (sym. C-H def.), 3055 (sym. aromatic C-H str.), 1550 (aromatic $\mathrm{C}=\mathrm{C}$ str.), 1610 (C=N str.), 1307 (C-N str.), 1035 (-C-O-C str.), ${ }^{1} \boldsymbol{H}$ NMR (DMSO-d ( $\left._{6}\right)$ $\delta\left(\right.$ ppm): $3.82\left(3 \mathrm{H}\right.$, singlet, $\left.-\mathrm{OCH}_{3}\right), 6.80-6.86$ $(2 \mathrm{H}$, multiplet, Ar- $\mathrm{CH}), 7.18-7.22$ (2H, doublet, Ar- $\mathrm{CH}), 7.61-7.65$ (2H, doublet, Ar- $\mathrm{CH}), 7.70-$ $7.74(2 \mathrm{H}$, doublet, Ar- $\mathrm{CH}), 8.43(1 \mathrm{H}$, singlet, $=\mathrm{CH}-), 11.50(1 \mathrm{H}$, singlet, $-\mathrm{NH}-), 12.10(1 \mathrm{H}$, singlet, $-\mathrm{OH}), \boldsymbol{M S}:(\mathrm{m} / \mathrm{z})=270.28$

JB-3: IR ( $\left.\mathbf{c m}^{-1}, \mathbf{K B r}\right): 3481$ (-OH str.), 2933 (sym. C-H str.), 1381 (sym. C-H def.), 3005 (sym. aromatic C-H str.), 1562 (aromatic $\mathrm{C}=\mathrm{C}$ str.), 1620 (C=N str.), 1232 (C-N str.), ${ }^{1} \boldsymbol{H} \boldsymbol{N M R}$ (DMSO-d $\boldsymbol{d}_{\boldsymbol{\sigma}} \boldsymbol{\delta}$ (ppm): 6.91-6.98 (3H, multiplet, Ar-CH), 7.25-7.27 (2H, doublet, Ar$\mathrm{CH})$, 7.69-7.74 (2H, doublet, Ar-CH), 7.79-7.83 $(2 \mathrm{H}$, doublet, Ar- $\mathrm{CH}), 8.43(1 \mathrm{H}$, singlet, $=\mathrm{CH}-$ ), $11.59(1 \mathrm{H}$, singlet, $-\mathrm{NH}-), 12.15(1 \mathrm{H}$, singlet, $-\mathrm{OH}), \boldsymbol{M S}:(\boldsymbol{m} / \boldsymbol{z})=240.25$

JB-4: IR ( $\left.\mathbf{c m}^{-1}, \mathbf{K B r}\right): 3454$ (-OH str.), 3059 (sym. C-H str.), 1371 (sym. C-H def.), 3119 (sym. aromatic C-H str.), 1533 (aromatic $\mathrm{C}=\mathrm{C}$ str.), 1635 (C=N str.), 1244 (C-N str.), $972(>\mathrm{C}=\mathrm{C}<),{ }^{1} \boldsymbol{H}$ NMR (DMSO-d $\left.\boldsymbol{d}_{6}\right)$ $\delta$ (ppm): 6.89-6.92 (2H, multiplet, Ar-CH), 7.22-7.25 (2H, doublet, Ar-CH), 7.69-7.74 (2H, doublet, Ar- $\mathrm{CH}$ ), 7.79-7.82 (3H, doublet, Ar$\mathrm{CH})$, 7.95-7.99 $(2 \mathrm{H}$, doublet, $-\mathrm{CH}=\mathrm{CH}-), 8.43$ $(1 \mathrm{H}$, singlet, $=\mathrm{CH}-), 11.58(1 \mathrm{H}$, singlet, $-\mathrm{NH}-)$, $12.15(1 \mathrm{H}$, singlet, $-\mathrm{OH}), \boldsymbol{M S}:(\mathbf{m} / \mathbf{z})=266.29$ 
JB-5: $\quad$ IR ( $\left.\mathbf{c m}^{-1}, \mathbf{K B r}\right): 3194$ (-OH str.), 2912 (sym. C-H str.), 1375 (sym. C-H def.), 3053 (sym. aromatic C-H str.), 1560 (aromatic $\mathrm{C}=\mathrm{C}$ str.), 1629 (C=N str.), 1224 (C-N str.), ${ }^{1} \boldsymbol{H} \boldsymbol{N M R}$ (DMSO-d $\boldsymbol{d}_{6} \boldsymbol{\delta}$ (ppm): 6.92-6.98 (4H, multiplet, Ar- $\mathrm{CH}$ ), 7.25-7.28 (2H, doublet, Ar$\mathrm{CH})$, 7.73-7.76 (2H, doublet, $\mathrm{Ar}-\mathrm{CH}), 8.42(1 \mathrm{H}$, singlet, $=\mathrm{CH}-), 11.56(1 \mathrm{H}$, singlet, $-\mathrm{NH}-), 12.10$ $(2 \mathrm{H}$, singlet, $-\mathrm{OH}), \boldsymbol{M S}:(\boldsymbol{m} / \boldsymbol{z})=256.25$

JB-6: IR ( $\left.\boldsymbol{c m}^{-1}, \boldsymbol{K B} \boldsymbol{B r}\right): 3217$ (-OH str.), 2926 (sym. C-H str.), 1352 (sym. C-H def.), 3061 (sym. aromatic C-H str.), 1558 (aromatic $\mathrm{C}=\mathrm{C}$ str.), 1604 (C=N str.), 1220 (C-N str.), ${ }^{1} \boldsymbol{H}$ NMR (DMSO-d $)$ o(ppm): 6.83-6.88 (4H, multiplet, Ar-CH), 7.21-7.24 (2H, doublet, Ar$\mathrm{CH}), 7.71-7.74(2 \mathrm{H}$, doublet, $\mathrm{Ar}-\mathrm{CH}), 8.40(1 \mathrm{H}$, singlet, $=\mathrm{CH}-), 11.53(1 \mathrm{H}$, singlet, $-\mathrm{NH}-), 12.02$ $(1 \mathrm{H}$, singlet, $-\mathrm{OH}), \boldsymbol{M S}:(\mathrm{m} / \mathrm{z})=285.25$

JB-7: IR ( $\left.\mathbf{c m}^{-1}, \mathbf{K B r}\right): 3250$ (-OH str.), 2899 (sym. C-H str.), 1350 (sym. C-H def.), 3082 (sym. aromatic C-H str.), 1606 (aromatic $\mathrm{C}=\mathrm{C}$ str.), 1631 (C=N str.), 1230 (C-N str.), ${ }^{1} \boldsymbol{H}$ NMR (DMSO-d $\boldsymbol{d}_{6}$ ) $\boldsymbol{\delta}$ (ppm): 6.89-6.93 $(3 \mathrm{H}$, multiplet, Ar-CH), 7.22-7.25 (2H, doublet, Ar$\mathrm{CH})$, 7.69-7.74 (2H, doublet, Ar-CH), $7.79(1 \mathrm{H}$, singlet, $\mathrm{Ar}-\mathrm{CH}), 8.43(1 \mathrm{H}$, singlet, $=\mathrm{CH}-), 11.56$ $(1 \mathrm{H}$, singlet, $-\mathrm{NH}-), 12.13(1 \mathrm{H}$, singlet, $-\mathrm{OH})$, MS: $(\mathbf{m} / z)=285.25$

\section{Antibacterial activity}

The antibacterial activity of all the azomethines against both Gram positive and Gram negative bacteria (Figures 1 and 2) respectively in both the solvents. Figure 1 shows that against B. subtilis, JB-4 showed maximum inhibition in both the solvents which is followed by JB-1. JB-3 and JB-7 also showed inhibition but only in DMF. Other compounds had no effect against B. subtilis in both the solvents.

Against S. aureus, again JB-4 showed inhibition in both the solvents and inhibition is slightly higher in DMF than DMSO. JB-6 also exhibited inhibition in DMF only. All other azomethines are not effective in both solvents. This suggests that compound structure and solvent play an important role in inhibition. In the present case, DMF is found to be good solvent against these selected Gram positive bacteria.
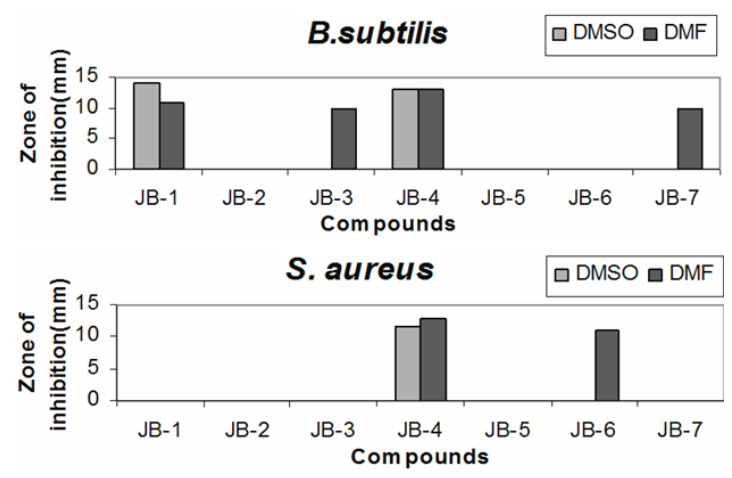

Figure 1: Antibacterial activity of azomethines against Gram positive bacteria in DMSO and DMF.

All the azomethines have methyl salicylate as central moiety. The side chains are different. Thus, in different solvents, different side chains show different activity. JB-4 has cinnamaldehyde as side chain, which is observed to be most effective in both the solvents.
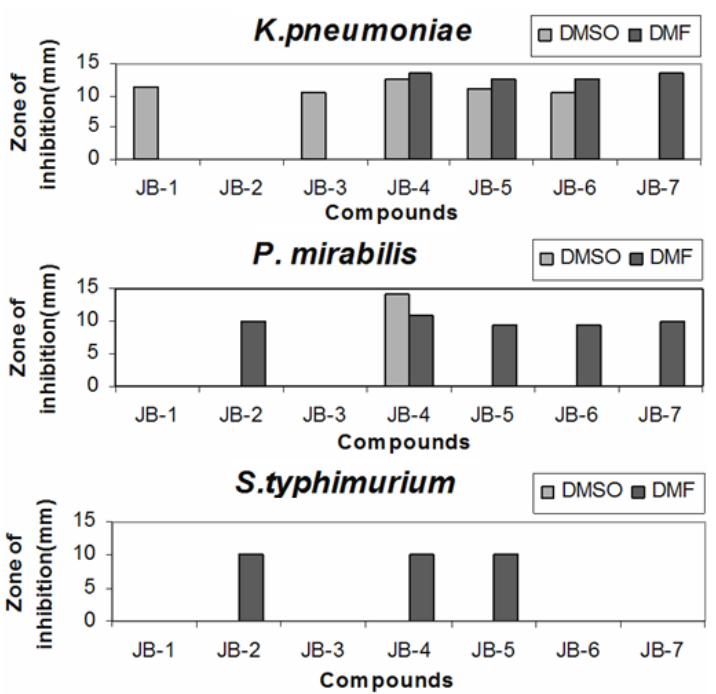

Figure 2: Antibacterial activity of azomethines against Gram negative bacteria in DMSO and DMF.

Figure 2 shows that more compounds exhibited inhibition against Gram negative bacteria. Against K. pneumonia, only JB-2 is found to be inactive in both the solvents. JB-4, JB-5 and JB-6 showed inhibition in both the solvents whereas JB-1 and JB-3 showed inhibition only in DMSO. JB-7 is effective in 
Shipra Baluja

Table I. Physical constants of Azomethines

\begin{tabular}{|c|c|c|c|c|c|c|}
\hline Compound Code & $\mathbf{R}$ & M.F. & M. Wt. g & $\mathbf{R}_{\mathrm{f}}$ Value* & M.P. ${ }^{0} \mathrm{C}$ & $\%$ Yield \\
\hline JB-1 & $4-\mathrm{CH}_{3}-\mathrm{C}_{6} \mathrm{H}_{4-}$ & $\mathrm{C}_{15} \mathrm{H}_{14} \mathrm{~N}_{2} \mathrm{O}_{2}$ & 254.28 & 0.54 & 110 & 65.7 \\
\hline JB-2 & $4-\mathrm{OCH}_{3}-\mathrm{C}_{6} \mathrm{H}_{4-}$ & $\mathrm{C}_{14} \mathrm{H}_{14} \mathrm{~N}_{2} \mathrm{O}_{3}$ & 270.28 & 0.48 & 90 & 40.8 \\
\hline JB-3 & $\mathrm{C}_{6} \mathrm{H}_{5^{-}}$ & $\mathrm{C}_{14} \mathrm{H}_{12} \mathrm{~N}_{2} \mathrm{O}_{2}$ & 240.25 & 0.57 & 100 & 52.4 \\
\hline JB-4 & $-\mathrm{CH}=\mathrm{CH}-\mathrm{C}_{6} \mathrm{H}_{5}-$ & $\mathrm{C}_{16} \mathrm{H}_{14} \mathrm{~N}_{2} \mathrm{O}_{2}$ & 266.29 & 0.61 & 115 & 67.0 \\
\hline JB-5 & $2-\mathrm{OH}-\mathrm{C}_{6} \mathrm{H}_{4^{-}}$ & $\mathrm{C}_{14} \mathrm{H}_{12} \mathrm{~N}_{2} \mathrm{O}_{3}$ & 256.25 & 0.42 & 130 & 46.6 \\
\hline JB-6 & $2-\mathrm{NO}_{2}-\mathrm{C}_{6} \mathrm{H}_{4-}$ & $\mathrm{C}_{14} \mathrm{H}_{11} \mathrm{~N}_{3} \mathrm{O}_{4}$ & 285.25 & 0.64 & 120 & 55.5 \\
\hline JB-7 & $3-\mathrm{NO}_{2}-\mathrm{C}_{6} \mathrm{H}_{4-}$ & $\mathrm{C}_{14} \mathrm{H}_{11} \mathrm{~N}_{3} \mathrm{O}_{4}$ & 285.25 & 0.47 & 125 & 58.3 \\
\hline
\end{tabular}

* Ethyl acetate : Hexane:- 2:8

Table II. Drug likeness score of Azomethines

\begin{tabular}{cccccccccccc}
\hline code & $\begin{array}{c}\text { Mi } \\
\text { LogP }\end{array}$ & $\begin{array}{c}\text { log } \\
\mathbf{P}\end{array}$ & \multirow{2}{*}{ TPSA } & $\begin{array}{c}\mathbf{N} \\
\text { atom }\end{array}$ & $\begin{array}{c}\mathbf{N} \\
\text { ON }\end{array}$ & nOHNH & $\begin{array}{c}\mathbf{N} \\
\text { viol. }\end{array}$ & $\begin{array}{c}\mathbf{N} \\
\text { rotb }\end{array}$ & $\begin{array}{c}\mathbf{n} \\
\text { ring }\end{array}$ & $\begin{array}{c}\mathbf{N} \\
\text { rigid B }\end{array}$ & \multirow{2}{*}{ MR } \\
\hline JB-1 & 4.04 & 3.431 & 61.69 & 19 & 4 & 2 & 0 & 3 & 2 & 16 & 80.35 \\
JB-2 & 3.64 & 2.646 & 70.92 & 20 & 5 & 2 & 0 & 4 & 2 & 16 & 82.71 \\
JB-3 & 3.59 & 3.039 & 61.69 & 18 & 4 & 2 & 0 & 3 & 2 & 15 & 76.07 \\
JB-4 & 3.81 & 3.944 & 61.69 & 20 & 4 & 2 & 0 & 4 & 2 & 16 & 86.31 \\
JB-5 & 3.53 & 2.536 & 81.92 & 19 & 5 & 3 & 0 & 3 & 3 & 16 & 77.67 \\
JB-6 & 3.50 & 2.834 & 107.5 & 21 & 7 & 2 & 0 & 4 & 2 & 17 & 79.29 \\
JB-7 & 3.52 & 2.623 & 107.51 & 21 & 7 & 2 & 0 & 4 & 2 & 17 & 79.29 \\
\hline
\end{tabular}

Table III. Bioactivity score of Azomethines

\begin{tabular}{ccccccc}
\hline Compound code & GPCRL & ICM & KI & NRL & PI & EI \\
\hline JB-1 & -0.58 & -0.91 & -0.64 & -0.65 & -0.85 & -0.51 \\
JB-2 & -0.51 & -0.85 & -0.55 & -0.56 & -0.75 & -0.45 \\
JB-3 & -0.61 & -0.86 & -0.67 & -0.69 & -0.87 & -0.48 \\
JB-4 & -0.34 & -0.82 & -0.72 & -0.52 & -0.62 & -0.32 \\
JB-5 & -0.51 & -0.90 & -0.59 & -0.61 & -0.71 & -0.44 \\
JB-6 & -0.65 & -0.83 & -0.71 & -0.52 & -0.81 & -0.60 \\
JB-7 & -0.60 & -0.82 & -0.62 & -0.59 & -0.80 & -0.53 \\
\hline
\end{tabular}

DMF only against this bacterial strain. Thus, against $K$. pneumonia, Thus, again cinnamaldehyde proved to be more effective in DMF and DMSO whereas JB-2 containing $p$-methoxy benzaldehyde as side chain is found to be non effective in both the solvents.

Against P. mirabilis, again JB-4 exhibited inhibition in both the solvents. JB-2, JB-5, JB-6 and JB-7 had minimum inhibition only in DMF whereas JB-1 and JB-3 are not effective at all in both the solvents.

Against S. typhimurium, only JB-2, JB-4 and JB-5 had inhibition in DMF. All other azomethines are non effective in both solvents.

\section{Molecular descriptors and prediction of bioactivity score}

The molecular descriptors and bioactivity scores are evaluated by molinspiration and DruLito softwares (Tables II, III and IV).

It is observed that for all the seven compounds, miLog $\mathrm{P}$ values are less than 5, molecular weight is less than 500, and number of hydrogen bond acceptors is upto 5 whereas number of hydrogen bond donors is zero. The number of violations (nviol) is zero so, Lipinski's rule is obeyed by these compounds. The molecular weight, $\log \mathrm{P}$, molar refractions of studied compounds follow rules of Ghose filter but for three compounds, number of total number of atoms is less than 20 . 
The studied compounds violate MDDRlike rule because all the compounds have number of rings less than 3 , number of rigid bonds less 18 and number of rotatable bonds less than 6 . So, the studied compounds are not much favorable drug like molecules.

This is further supported by bioactivity score of these compounds. If an organic molecule is bioactive, its bioactivity score should be greater than zero. If it is between -5.0 to 0.0 then it is moderately active and if it is less than -5.0 , it is inactive. Table IV shows that all the different parameters are negative for the studied compounds and are in between -1.0 to 0.0 indicating that these compounds are moderately active.

\section{CONCLUSION}

The inhibition depends upon three S; solvent, structure and strain. Out of the two solvents studied, DMF is proved to be better solvent. The different side chains affect differently on different bacterial strains in different solvents. Overall, the azomethine with cinnmaldehyde showed maximum inhibition. This implies that the methyl salicylate moiety with cinnamaldehyde side chain can be used as a lead molecule for drug designing.

The molecular descriptors and bioactivity score of studied compounds also predict moderate activity of these compounds.

\section{ACKNOWLEDGEMENTS}

Authors are thankful of Heads of Chemistry and Bioscience Departments for providing necessary facilities.

\section{REFERENCES}

Ajabshir, S. Z., Niasari M. S., Hamadanian M., 2015. Praseodymium oxide nanostructures: novel solvent-less preparation, characterization and investigation of their optical and photo catalytic properties. RSC Adv. 5: $33792-$ 33800.

Al-Amiery A. A., Al-Majedy Y. K., Ibrahim H. H., Al-Tamimi-Al-Amiery A. A., 2012. Antioxidant, antimicrobial, and theoretical studies of the thiosemi carbazone derivative Schiff base 2-(2imino-1-methylimidazolidin-4-ylidene) hydrazine carbothioamide (IMHC). Org.
Med. Chem. Lett., 2, 4. doi: 10.1186/21912858-2-4.

Álvarez-Fernández E., Cancelo A., Diaz-Vega C., Capita R., Alonso-Calleja C., 2013. Antimicrobial resistance in E. coli isolates from conventionally and organically reared poultry: A comparison of agar disc diffusion and Sensi Test Gramnegative methods. Food Control, 30: 227234.

Asadi M., Sarvestani A. H., 2001. Synthesis, characterization, and thermodynamics of tertiary phosphine cobalt(III) Schiff-base complexes. Can. J. Chem. 79: 1360 -1365.

Aydogan F., Öcal N., Turgut Z., Yolacan C., 2011. Transformations of aldimines derived from pyrrole-2-carbaldehyde and Synthesis of thiazolidino-fused compounds. Bull Korean Chem. Soc. 22: 476-480

Bardley, M. P., 2002. An overview of the diversity represented in commercially available databases. J. Comp. Aid. Mol. Div., 16: 301-309.

Bekhil A. A., Heshan, Fahwy T.V., Baraka A., 2003. Design and synthesis of some substituted $1 H$-pyrazolyl-thiazolo[4,5- $d$ ] pyrimidines as anti-inflammatory-anti microbial Agents Eur. J. Med. Chem. 38: $27-36$

Ceglowski M., Schroeder G., 2015. Preparation of porous resin with Schiff base chelating groups for removal of heavy metal ions from aqueous solutions, Chem. Eng. J. 263: 402-411.

Ghose, A. K, Viswanadhan, V. N, Wendoloski, J. J., 1999. A knowledge-based approach in designing combinatorial or medicinal chemistry libraries for drug discovery. 1. A qualitative and quantitative characterization of known drug databases. J Comb. Chem. 1: 55-68.

Hashimoto T., Kimura H., Kawamata Y., Maruoka K., 2012., A Catalytic Asymmetric Ugi-type Reaction With Acyclic Azomethine Imines. Ang. Chem. Int. Ed. 51: 7279-7281.

Hesping L., Biswas A., Daniliuc C.G., Lichtenfeld C. M., Studer A., 2015.

Stereo selective Lewis base catalyzed formal 1,3-dipolar cycloaddition of 
azomethine imines with mixed anhydrides. Chem. Sci. 6: 1252-1257

Hoz A., Diaz-Ortiz A., Moreno A., SanchezMigallon A., Prieto P., Carrillo J. R., Vazquez E., Gomez M. V., Herrero, M. A., 2007. Microwave-Assisted Reactions in Heterocyclic Compounds with Applications in Medicinal and Supramolecular Chemistry. Comb. Chem. High Thro. Screen. 10: 877- 902.

Lipinski C. A., 2004. Lead- and drug like compounds: the rule of five revolution. Drug Discovery Today: Techn., 337-341.

Lipinski C. A., Lombardo F., Dominy B. W., Feeney P. J., 1997. Experimental and computational approaches to estimate solubility and permeability in drug discovery and development settings. $A d v$. Drug Del. Revs. 23: 3-25.

Oprea, T. I., 2000. Property distribution of drug-related chemical databases. J. Comput. Aid. Mol. Des., 14: 251-264.

Pandey S. N., Sriram D., Nath G., DeClercq E., 1999. Synthesis, antibacterial, antifungal and anti-HIV activities of Schiff and Mannich bases derived from isatin derivatives and N-[4-(4'chlorophenyl)thiazol-2-yl]

thiosemicarbazide. Eur. J. Pharma. Soc. 9: 25-31.

Singh P., Kaur P., Luxami V., Kaur S., Kumar S., 2007. Syntheses and anti-cancer activities of 2-[1-(indol-3-yl-/pyrimidin- 5-yl-/pyridine-2-yl-/quinolin-2-yl)-but-3enyl amino]-2-phenyl ethanols. Bioorg. Med. Chem. 15: 2386-2395.

Sriram D., Yogeeswari P., Kumar, T. G. A., 2005. Microwave assisted synthesis and anti-HIV activity of 2, 3-diaryl-1,3thiazolidin-4-ones. Ind. J. Pharm. Sci. 67: 96-499.

Sztanke K., Maziarka A., Osinka A., Sztanke M., 2013. An insight into synthetic Schiff bases revealing antiproliferative activities in vitro. Bioorg. Med. Chem.http://www.sciencedirect.com/sci ence/journal/09680896/21/13 21: 3648-3666.

Veber, D. F., Johnson, S. R., Cheng, H. Y., Smith, B. R., Ward, K. W., Kopple, K. D., 2002. Molecular properties that influence the oral bioavailability of drug candidates. J. Med. Chem. 45:2615-2623.

Verma G., Marella A., Mohammad S., Mymoona A., Mohammad R. A., Mohammad M. A., 2014. A review exploring biological activities of hydrazones. J Pharm Bioallied Sci. 6: 6980.

Yurti A., Bereket G., Kivrak A., Balaban A., Erk B., 2005. Corrosion-Effect of Schiff bases containing pyridyl group as corrosion inhibitors for low carbon steel in $0.1 \mathrm{M} \mathrm{HCl}$. J. Appl. Electrochem., 35: 1025-1032. 